\title{
Biological variation of high sensitivity cardiac troponin-T in stable dialysis patients: implications for clinical practice
}

DOI 10.1515/cclm-2015-0885

Received September 11, 2015; accepted September 21, 2015; previously published online October 23, 2015

Keywords: biological variation; haemodialysis; troponin.

To the Editor,

We read with great interest Fahim et al.'s paper on biological variation of high-sensitivity troponin in stable haemodialysis patients [1]. In keeping with other studies, the authors demonstrated a low index of individuality in stable haemodialysis patients and conclude that troponin results are best interpreted using serial measurements in this group of patients [2,3]. However, a number of factors that may impact the clinical care of haemodialysis patients who have a high cardiovascular morbidity and mortality were not addressed.

The range in troponin concentrations in the study from $8 \mathrm{ng} / \mathrm{L}$ to $241 \mathrm{ng} / \mathrm{L}$ may result in overestimation or underestimation of the imprecision of troponin at different concentrations as its imprecision varies across different concentrations. This means that the computed assay imprecision may not be representative at different troponin concentrations. This is a complex issue that may have implications on the application of biological variation indices in clinical practice.

The biological variation indices were computed using pre-dialysis blood samples. We know that troponin concentration may vary in relation to dialysis with reduction during haemodialysis and a gradual increase prior to the next dialysis episode [4]. There is the possibility of myocardial stunning during dialysis which may increase

*Corresponding author: Wycliffe Mbagaya, Weston General Hospital, Weston-Super-Mare, BS23 4TQ, UK, E-mail: mbagaya@doctors.net.uk

Ahai Luvai: North Cumbria University Hospitals NHS Trust, Carlisle, CA2 7HY, UK troponin concentrations [5]. Since coronary events may occur at any time in relation to dialysis. The application of this data may be challenging.

While we agree that troponin results in stable haemodialysis patients are best interpreted using serial measurements rather than using single readings, further guidance in relation to frequency of measurement of troponin and what constitutes significant change in this group is required.

Author contributions: All the authors have accepted responsibility for the entire content of this submitted manuscript and approved submission.

Research funding: None declared.

Employment or leadership: None declared.

Honorarium: None declared.

Competing interests: The funding organisation(s) played no role in the study design; in the collection, analysis, and interpretation of data; in the writing of the report; or in the decision to submit the report for publication.

\section{References}

1. Fahim MA, Hayen AD, Horvath AR, Dimeski G, Coburn A, Tan KS, et al. Biological variation of high sensitivity cardiac troponin-T in stable dialysis patients: implications for clinical practice. Clin Chem Lab Med 2015;53:715-22.

2. Aakre KM, Røraas T, Petersen PH, Svarstad E, Sellevoll H, Skadberg $\emptyset$, et al. Week-to-week biological variation in Cardiac Troponin T and Cardiac Troponin I in hemodialysis patients and healthy controls. Clin Chem 2014;60:838-47.

3. Mbagaya W, Luvai A, Lopez B. Biological variation of cardiac troponin in stable haemodialysis patients. Ann Clin Biochem 2015;52:562-8.

4. Pianta TJ, Horvath AR, Ellis VM, Leonetti R, Moffat C, Josland EA, et al. Cardiac high-sensitivity troponin T measurement: a layer of complexity in managing haemodialysis patients. Nephrology 2012;17:636-41.

5. McIntyre CW, Burton JO, Selby NM, Leccisotti L, Korsheed S, et al. Hemodialysis-induced cardiac dysfunction is associated with an acute reduction in global and segmental myocardial blood flow. Clin J Am Soc Nephrol 2008;3:19-26. 